\title{
A Normative Theory of Dynamic Capabilities: Connecting Strategy, Know-How, and Competition
}

\section{Citation}

Pisano, Gary P. "A Normative Theory of Dynamic Capabilities: Connecting Strategy, Know-How, and Competition." Harvard Business School Working Paper, No. 16-036, September 2015.

\section{Permanent link}

http://nrs.harvard.edu/urn-3:HUL.InstRepos:23492374

\section{Terms of Use}

This article was downloaded from Harvard University's DASH repository, and is made available under the terms and conditions applicable to Open Access Policy Articles, as set forth at http:// nrs.harvard.edu/urn-3:HUL.InstRepos:dash.current.terms-of-use\#OAP

\section{Share Your Story}

The Harvard community has made this article openly available.

Please share how this access benefits you. Submit a story.

\section{Accessibility}




\section{A Normative Theory of Dynamic Capabilities: Connecting Strategy, Know-How, and Competition}

Gary P. Pisano

Working Paper 16-036 


\section{A Normative Theory of Dynamic Capabilities: Connecting Strategy, Know-How, and Competition}

Gary P. Pisano

Harvard Business School

Working Paper 16-036 


\section{A Normative Theory of Dynamic Capabilities: \\ Connecting Strategy, Know-How, and Competition}

\section{Working Paper}

Draft 2.5

September 25, 2015

Gary P. Pisano

Harry E. Figgie Professor of Business Administration

Harvard Business School

* I would like to thank Pamela Adams, Giada di Stefano, Giovanni Dosi, Pankaj Ghemawat, Shane Greenstein, Franco Malerba, Michael Tushman, and Eric Van der Steen for many helpful comments on an earlier draft of this paper. All errors and shortcomings are the sole responsibility of the author. The financial support of the Harvard Business School Division of Faculty Research and Development is gratefully acknowledged. 


\begin{abstract}
The field of strategy has mounted an enormous effort to understand, define, predict, and measure how organizational capabilities shape competitive advantage. While the notion that capabilities influence strategy dates back to the work of Andrews (1971), attempts to formalize a "capabilities based" approach to strategy only began to take shape in the past twenty years. In particular, the publication of Teece and Pisano (1994) and Teece, Pisano, and Shuen (1997) work on "dynamic capabilities" triggered a flood of debate and discussion on the topic. Because strategy is a normative field, its theories must be evaluated in terms of how well they inform and impact practice. Judging by this standard, the dynamic research capabilities research program has come up short. It has become mired in endless debates about definitions and has engaged obsessively in an elusive search for properties that make organizations adaptable. In this paper, I argue that the research program on dynamic capabilities needs to be reset around the fundamental strategic problem facing firms: how to identify and select capabilities that lead to competitive advantage. I frame the firm's capability strategy problem as one of choosing among different types of capability enhancing investments, ranging from general-purpose know-how to application-specific know-how. The framework also draws a distinction between investments designed to deepen the firm's existing base of capabilities and those designed to broaden its repertoire into new realms. I explore the applicability of this framework to three general types of competitive circumstances: stable product market competition, Schumpeterian entry, and Penrosian dynamics. A major goal of the paper is to identify important gaps in our theoretical and empirical knowledge that should be a focus for future scholarly research.
\end{abstract}




\title{
A Normative Theory of Dynamic Capabilities: \\ Connecting Strategy, Know-How, and Competition
}

\author{
Gary P. Pisano \\ Harry E. Figgie Professor of Business Administration \\ Harvard Business School
}

Draft 2.5

September 25, 2015

\section{Introduction}

The field of strategy has mounted an enormous effort to understand, define, predict, and measure how organizational capabilities shape competitive advantage. While the notion that capabilities influence strategy dates back to the work of Andrews $(1971)^{1}$, attempts to formalize a "capabilities based" approach to strategy only began to take shape in the past twenty years. In particular, the publication of Teece and Pisano (1994) and Teece, Pisano, and Shuen (1997) work on "dynamic capabilities" triggered a flood of debate and discussion on the topic. ${ }^{2}$ Despite such a concerted intellectual effort, progress toward a strategic theory of capabilities or even a coherent framework has been disappointing. For instance, in a comprehensive review of the literature on the topic, Peteraf et al. (2013) put in starkly: "From the intensity of this research effort and evident interest in the topic, one might surmise that there exists a common understanding of dynamic capabilities. This is far from the case. The construct remains open to a variety of conceptualizations and interpretations concerning even its most basic aspects, including how dynamic capabilities are defined." The attempt to parse the dynamic capabilities concept at everfiner levels of detail has lead to multiple competing definitions (for a comparison, see Dosi et al. 2008). Even the most ardent supporters of a dynamic capabilities approach to strategy would have to admit that the framework has made little progress theoretically, and has certainly gained

${ }^{1}$ Other early antecedents include Hayes (1985), Winter (1987), and Prahalad and Hamel (1990)

${ }^{2}$ According to a recent review by Peteraf et al. (2013), since 2006 alone, articles on "dynamic capabilities" have appeared in management journals at a rate of more than 100 per year. 
even less traction among practitioners.

Perhaps this lack of convergence should not be surprising. Both capabilities and strategy are broad realms, lending themselves to a range of perspectives. Debate may simply reflect a healthy process of generation and selection among multiple competing ideas, especially early in the intellectual life cycle of a concept (Helfat and Peteraf 2009). In this essay, I want to suggest a deeper underlying problem: the debate has become obsessed with the wrong questions. Specifically, the vast majority of literature on dynamic capabilities has focused on questions related to definitions: What exactly is a dynamic capability? How is such a capability different from other capabilities? What are the organizational determinants of such "dynamic capabilities" (whatever they may be)? The search for an elusive set of "dynamic capabilities" has become the holy grail of the literature. Clear definitions, of course, are important, but definitions are tools, and tools are only useful when they are designed to solve a specific problem. A terminology debate about a theory without a clear understanding of the problem the theory is trying to solve is unproductive. Lost in the froth of academic debate on terminology has been the very basic problems a capabilities-based approach to strategy should be seeking to solve.

In this paper, I argue that rather than chasing after an elusive property of enterprises called "dynamic capabilities", we should instead focus on the problem of how competition in product markets and competition to create capabilities are linked. I start with the (original) premise of dynamic capabilities (Teece and Pisano 1994, and Teece, Pisano, and Shuen 1997) that capability identification, selection, and creation is an important (practical) strategic decisionjust as important to competitive performance as decisions about which markets to enter, how to position, in which markets to exploit existing resource position, how to deter entry, pricing, and other "traditional" strategic variables. Just as firms compete in product markets, they also compete to create technological, operational, and organizational capabilities that provide them advantage in those product markets. Decisions about product market entry and position, and decisions about capability creation are intimately linked. Investments in capabilities create 
strategic options for competition in product markets. The job of a capabilities-based theory of strategy should be to provide conceptual and practical insights about these links. More specifically, a capability-based theory of strategy should identify the choices available to firms and the consequences of those choices under different competitive circumstances.

I frame the firm's capability strategy problem as one of choosing among investments in different types of capabilities. Throughout, I will keep my definition of capabilities fairly basic. Following Winter (2003), a capability is a collection of organizational routines that enable a firm to perform some set of tasks on a repeatable or consistent basis. The term know-how and capabilities will be used interchangeability. At any point in time, a firm possesses a repertoire of capabilities that span a continuum from highly general-purpose (e.g. mechanical engineering, organic chemistry, assembly manufacturing, quality improvement, financial management, etc.) to highly application-specific (compact car design, immunotherapeutic cancer drug discovery, retail banking in a particular region, high-volume semiconductor manufacturing, etc.). The firm's capability strategy involves choices between deepening their existing capabilities versus broadening their repertoire to include new sets of capabilities. Obviously, firms can do both, but resource constraints mean that it must make choices at the margin. In addition, a firm's capability choices are partially constrained-they are neither complete prisoners of their past nor can they change instantly and infinitely. A robust capability-based theory of strategy should provide guidance to managers about the nature of these constraints (e.g. which choices are economically feasible?) and the implications of their capability decisions across a broad range of competitive circumstances.

For purposes of illustration, the paper examines capability strategy choices in three fairly common types of competitive configurations that vary in both the structure of supply (who are the competitors) and demand (who are the customers): 1) Stable Product Market Competition: competing against existing rivals in existing markets (e.g. Honda vs. Toyota in the automobile market) 2) Schumpeterian Entry: competing against new entrants in an existing market (e.g. 
Honda vs. Tesla in automobiles) 3) Penrosian Dynamics: competing against new rivals as a result of diversifying into new markets (e.g. Honda's entry into light jets). By including consideration of "stable product markets", this paper departs from the existing dynamic capabilities literature that has largely concerned itself with so-called "turbulent" environments. As discussed later, firms in a broad range of environments (including some seemingly stable ones like automobiles) compete vigorously in the creation of new capabilities. A capability-based theory of strategy should be able to address capability-based competition in the full range of competitive circumstances a firm may face.

I close the essay by evaluating our state of theoretical and empirical knowledge in each of these three circumstances, and suggest important gaps in our understanding that should be tackled in future research.

\section{Focal Questions For a Capabilities-Based Theory of Strategy}

Theory development is one of identifying and filling gaps between causal explanations and observed phenomenon (Kuhn 1970). A capabilities-based theory of strategy, like any theory, needs to start with the gap between what we can see and what we can explain. Strategic theory is, by and large, a normative endeavor. For a normative field, like strategy, the search for new theory begins when existing theories cannot explain or predict better outcomes, and thus fail to provide practical guidance. Such gaps suggest new questions, and these should become focal points for empirical exploration and theory development.

The strategy field has been undergoing this "gap filling" process for more than five decades. The field of business strategy emerged in the 1960s to address the question: what can companies do to gain advantage over their competitors? But underneath this normative question lied a theoretical question (at least implicitly): why are some firms more successful (long term profitability, growth, etc.) than others? This question was based on the observation (both casual and later statistical) that some firms were more profitable than others. This phenomenon also 
presented an interesting puzzle when viewed against traditional economic theory in the pre-1950 period. Under standard economic theory, barring monopoly or collusive oligopoly, competitive forces drive an equilibration between supply and demand, and above normal profits disappear. Firms capturing rents over anything but a transitory period are anomalies. Unfortunately (for standard economic theory) there were too many anomalies to be ignored, and the search began for theories that might explain sustained "excess" rents.

Research to tackle this problem was initiated by Edward Mason and Joe Bain in the 1930s, 1940s, and 1950s. They, and later their followers such as Nicholls, Markham, Peck, and Caves, conducted a series of industry case studies exploring the structural factors (e.g. entry barriers) that influenced the behavior of firms (e.g. pricing) and the overall performance of the industry. These empirical and theoretical works created the "structure-conduct-performance" paradigm of industrial organization and a body of underlying theories connecting various industry structure parameters to firm level behavioral variables (strategy) and economic performance. Utilizing the structure-conduct-performance paradigm as his base, Michael Porter (1980) developed a useful framework for strategy. As is well known today, Porter's "five forces" framework posited that firms can gain an advantage by selecting strategies that exploit underlying structural conditions of an industry (e.g. entry barriers, the potential for product differentiation). In Porter's framework, the central questions of strategy are: which industries should we enter and how should we position ourselves within those industries? Analytically, these questions are tackled by identifying industry features such as entry barriers and other forces that impede the equilibration of markets.

As a framework, "five forces" has been remarkably successful. It is logically consistent. It can explain the facts well (for instance, why are airlines, on average, much less profitable than pharmaceutical companies). It has held up well to empirical testing. It is flexible enough to handle a broad range of strategic contexts and problems. And it could be distilled into useful analytical tools and concepts to help practitioners make sense of the world. While subsequent work in 
economics, particularly game theory, expanded these notions and incorporated more sophisticated firm-to-firm interactions, and probed more deeply into specific strategic contexts (e.g. capacity strategies, entry deterrence), the basic edifice has been robust.

But there was a puzzle that Porter's and subsequent economic approaches could not explain: namely, the relatively high degree of intra-industry variability in profitability over long periods. Empirical studies (Lippman and Rumelt 1982, Rumelt 1984, Rumelt 1991) and numerous case studies suggested there was more to the picture than just picking the right industry or getting the positioning right. Many companies within the same industry following similar strategies had very different performance (consider discount airlines, brewers, semiconductor companies, car companies). Moreover, case studies and later empirical studies suggested that rivals in an industry were generally far from homogenous when it came to capabilities and resources. These observations lead to the development of resource-based theories of strategy (Wernerfelt 1984, Barney 1991, Amit and Schoemaker 1993).

Following Penrose (1959), resource based theorists adopted the idea that firms could be viewed as collections of resources. The resource-based theory of strategy sought to explain intraindustry performance differences with firm-specific (non-imitable) "resources": tangible and intangible assets like skills, capabilities, reputation, brand equity, etc. Given the theory's intellectual connection to Penrose, it is perhaps not surprising that resource-based theory made its most precise predictions on the matter of corporate diversification (e.g. Teece 1982, Montgomery and Wernerfelt 1988).

Resource-base theory does a good job explaining phenomena like why some types of corporate diversification strategies work better than others. It also provides a relatively coherent explanation for intra-industry differences in advantage. Resource-based theory, by and large, takes the resource endowments of firms as given. There were differences across firms, yes, but these were either largely outside the realm of the analysis, or just assumed to be a matter of 
history (see e.g. Barney 1986).

During the 1980 s and early 1990s, a series of studies largely undertaken by scholars outside the strategy field were creating another puzzle. Statistical and case studies of product development and operational performance (Abernathy et al. 1983; Garvin 1988: Hayes and Clark 1986: Clark and Fujimoto 1990: Pisano 1994: Iansiti 1994) suggested that some organizations do a better job creating and developing those capabilities that lead to sustained competitive advantage. Moreover, this line of work indicated that some firms were more capable of renewing their skills and building new competences. Resources (broadly defined) were not static.

Like Porter's five forces framework, resource-based theories had little to say about the dynamics of capability-creation. It could not explain why, for instance, Toyota had accumulated stronger capabilities in product development and manufacturing than General Motors. It could not predict whether a firm like Intel would maintain its lead in technology over a rival like AMD, even though such a capability advantage may be critical to Intel's competitive advantage in the microprocessor market. And resource-based theory provides little guidance to firms about the kind of capabilities they might attempt to develop in order to secure or sustain a competitive advantage (beyond general properties like inimitability and uniqueness). Such dynamics of capability accumulation were completely outside the realm of either Porter or resource-based frameworks.

Moreover, neither framework even identified capability creation as a question of strategic significance to the practitioner. A practitioner reading Porter would immediately recognize that it was critical for them to consider the questions: "What industries/product markets should we enter and how should we position ourselves in these?" The prescient strategy question is essentially identical in resource-based theories: what industries/product markets to enter and how to position 
the firm within those. ${ }^{3}$ A capabilities-based perspective asks practitioners to consider a different question: what capabilities should the firm nurture to gain a competitive advantage?

\section{The Dynamic Capabilities Framework}

Responding to this gap, Teece and Pisano (1994) and Teece, Pisano, and Shuen (1997) outlined a framework-generally referred to as "dynamic capabilities"--for understanding firm level capability differences. The "dynamic capabilities" framework conjectured that firm-level differences in capabilities were rooted in three factors:

1. Asset Positions: Following evolutionary economic and path-dependence logic, a firm's ability to change their future repertoire of capabilities is constrained by its current stock of capabilities. Teece and Pisano (1994) used the term "assets" broadly to define the legacy resources (knowledge, technical skills, organizational competences, etc.) that shaped the firm's options for future capability expansion.

2. Processes: Firms can "reconfigure" their asset positions by investments and other managerial interventions. But a firm's capacity to reconfigure is not unlimited. It depends on a set of 'higher-order' routines (like governance structures, resource allocation processes, management systems, etc.) that shape organizational adaptability. It is this capacity to reconfigure a firm's asset positions and specifically the "processes" that underlie this capacity that Teece and Pisano (1994) called its "dynamic capabilities."

3. Paths: Because most capabilities are cumulative and develop over time through a series of coordinated investments, they involve commitments to "paths", rather than discrete projects. A key strategic problem for firms is to identify and commit to paths for capability creation that lead to competitive advantage. Managerial discretion in the selection of paths_-along with constraints imposed by pre-existing asset positions and processes for

\footnotetext{
${ }^{3}$ The fundamental difference between the two frameworks is the underlying factors that should influence the answer (in Porter, structural characteristics of industry take center stage; in resource-based frameworks, consideration is given to the firm's unique resources).
} 
reconfiguration--can lead to differences in firm capabilities.

The dynamic capabilities framework had both descriptive and normative implications. It could be use to help explain firm-level differences. But, it also aspired to inform managers about how to make better capability decisions. The dynamic capabilities framework argued that these kinds of choices were important to a firm's competitive advantage, and thus should be a focal point for strategic analysis. The third leg of the framework—choices about paths—was the most explicitly normative, but the original formulations in Teece and Pisano (1994) and Teece, Pisano, and Shuen (1997) offered only high-level normative guidance. It was hoped at the time that future research would illuminate many more details and principles about how managers should make capability investment commitments.

Unfortunately, this is not the issue that became the focal point of "dynamic capabilities" literature. ${ }^{4}$ That literature has come to focus on the question of why some firms are more adaptable than others. Specifically, the literature has been consumed with the second leg of the framework---identifying and specifying exactly what "dynamic capabilities" are and how they contribute to a firm's capacity to adapt to change and reconfigure their competences and assets. This is important work, and has lead to interesting insights about organizational change. But such a capacity for change alone tells us nothing about competitive outcomes, other than the obvious fact that a more flexible firm will likely do better in a more uncertain environment. As Winter (2003, page 994) points out: "Some of the mystery and confusion surrounding the concept of dynamic capabilities arises from linking the concept too tightly to notions of generalized effectiveness at dealing with change and generic formulas for sustainable competitive advantage."

Telling managers they should create organizations that are adaptable is fine and developing good theories about what makes a firm adaptable is certainly a worthwhile endeavor.

\footnotetext{
${ }^{4}$ For excellent reviews, see Dosi (2008), Helfat and Peteraf (2009), and Peteraf et al. (2013)
} 
However, understanding the merits and drivers of organizational adaptability does not constitute the basis of a helpful theory of strategy. "How do I make my enterprise more adaptable?" is a very different question than "What capabilities should I attempt to create to gain a competitive advantage?" The former is not a strategy question, the latter is.

\section{Dynamics of Capability Accumulation}

A critical premise of a capabilities-based approach to strategy is that capabilities not only vary across firms, but these differences are the result of management choices. If capabilities do not vary across firms, or if such capability differences have nothing to do with management discretion, the prescient strategic question ("Which capabilities should we seek to create to gain an advantage?") is moot. What does the empirical evidence say?

As noted earlier, we have ample evidence that capabilities (of all stripes) vary significantly across firms even after controlling for a broad array of factors (like product mix, industry, capital stock, etc.) Historians like Chandler documented dramatic differences across firms in terms of administrative, operational, and distribution capabilities (Chandler 1990). Detailed empirical analyses of productivity show productivity differs significantly across firms (see e.g. Hayes and Clark 1986, Bloom and van Reenen 2007). We have ample empirical evidence from a variety of industries that quality differences (e.g. defect rates, yields) vary dramatically across firms within the same industry (e.g. Garvin 1988, Womack et al 1990). We know that operational flexibility varies significantly across firms (see Upton 1995). We know that product and process development capabilities (measured in terms of speed, engineering productivity, and development quality) vary significantly across firms (Clark and Fujimoto 1990, Pisano 1996, Iansiti 1998, Henderson and Cockburn 1994). We also know from numerous studies that sudden upheavals in an industry's underlying technology base can create large and persistent differences in technological capabilities across competitors (Dosi 1984, Malerba 1985, Abernathy and Clark 1985, Tushman and Anderson 1986, Henderson and Clark 1990, Christensen 1997). 
However, differences in capability are not enough to motivate the need for a capabilitiesbased theory of strategy. Two null hypotheses must first be evaluated. First, are these differences random? If random, then they are beyond management control (and thus, outside the realm of strategy). Second, are these differences purely a function of firm history (path dependence)? If this is true, then capabilities of a firm are once again beyond management control (and, again, outside the realm of strategy). For capabilities to be a "strategic variable", management must be able to influence their creation and evolution. They must be endogenously shaped by management decisions. If capability creation is either a purely random or completely determined process, then the third leg of the original "dynamic capabilities" framework is normatively irrelevant. Existing theories (such as resource-based theories) already help us understand how extant capabilities may be deployed for competitive advantage.

\section{Randomness: Can We Rule Out Luck?}

In an influential paper, Jay Barney (1986) argued that resource endowments of firms were a function of luck. That being the case, the paper asserted, the task of strategic management is to understand how best to exploit the firm's given endowments, rather than to manipulate those. If resources (including capabilities) are the outcome of a "dice-roll", then it makes little sense to focus on how to roll the dice; better to focus attention on what to do given that roll. Barney's argument is provocative. However, the vast majority of empirical and casebased evidence strongly contradicts it. Over the past three decades, a number of empirical investigations and case study research has been done to understand firm-level differences in productivity, quality, manufacturing flexibility, and product and process development. While a fullblown review of these findings is beyond the scope of this paper, a number of key streams of work are highlighted below.

Since the mid-1980s, a steady stream of empirical work has demonstrated clearly that there are significant differences in total factor productivity across firms and that these differences are systematically related to differences in management practice. Hayes and Clark (1985) 
conducted the first study in this vein. Using factory level data on total factor productivity across a small sample of firms, they identified differences in management practice as a significant driver of differences in productivity. More recently, analyzing survey data collected from 5850 firms across seventeen countries, Bloom and Van Reenen (2010) come to essentially the same conclusion as Hayes and Clark: "The patterns within our large sample of management data across firms and countries have led us to believe that one important explanation for the large differences in productivity between firms and countries-differences that cannot be readily explained by other factors-is variations in management practices. ${ }^{5}$ Similar results can be found for the research that has investigated inter-firm differences in quality (e.g. Garvin 1988, Womack et al. 1991) and manufacturing flexibility (Upton 1995).

An extensive body of research has also documented the role that differences in management practice play in R\&D capabilities. In a study of the global automobile industry, Clark and Fujimoto (1990) found that significant differences in product development lead times, engineering productivity, and development quality could be traced to specific management practices. The role of management in shaping product and process development capability can be found in numerous other studies, including lansiti's (1998) work on semiconductors and computers (1997), Pisano's work (1996) on pharmaceuticals and biotechnology, and Henderson and Cockburn's (1994) work on R\&D productivity in pharmaceuticals.

The mass of available empirical evidence on the drivers of such critical operating capabilities behind productivity, quality, manufacturing flexibility, and R\&D performance clearly indicates that "management matters." The notion that firm capabilities are somehow randomly distributed among firms is simply not tenable given the available empirical evidence.

\section{Path Dependence: Can We Rule Out Determinism?}

The concept of "path dependence"-meaning what happens today is a function of what

\footnotetext{
${ }^{5}$ Bloom and Van Reenen (2010) page 222.
} 
happened yesterday—has featured prominently in capabilities-based discussions of strategy (and as noted above, was a key pillar of the original "dynamic capabilities" framework). The general idea is that a firm's capabilities today are constrained by the capabilities it has accumulated in the past. This view is strongly rooted in ecological and evolutionary theories of the firm (see e.g. Hannan and Freeman 1977, Nelson and Winter 1982) that posit that strong inertial forces severely constrain organizations' capacity to adapt to environmental changes. Taken to its extreme, path dependence once again calls into question management's ability to shape capabilities. Some researchers have even gone as far as to call the strategic managers job "futile in the face of environmental disruptions" (Drew, Goldfarb, and Sarasvathy 2006). If the visible hand of management cannot shape an organization's capabilities, one just needs to understand starting positions and the rest is "set in stone."

The empirical evidence, however, casts serious doubt on strong-form path dependence arguments. Several studies have noted that the capacity for learning and adaptation varies dramatically across organizations, and these differences—once again-appear to be rooted in management actions, policies, and decisions (see. e.g. Bloom and van Reenen 2010). While a number of studies highlight the challenges industry incumbents face adapting their capabilities to dramatic technological changes (e.g. Tushman and Anderson 1984, Henderson and Clark 1990, Christensen 1997), failure to adapt is not inevitable. Henderson and Clark (1990), for instance, found organizations that successfully adapted to major "architectural" transitions in the photolithography business. Work by King and Tucci (2002) in the disk drive industry shows that an incumbent's experience in a previous market actually increased their probability of entering a new market. Others who have documented instances of organizational adaptation include Tripsas (1997), and O'Reilly and Tushman (2008). In summarizing the arguments for the adaptability of firms, O'Reilly and Tushman (2008, page 5) conclude:

For every well-known failure (e.g., Polaroid and Pan Am), there are firms like GKN, a 245 year-old maker of auto parts and aero-space materials, that began as a coal mining company, or the Harris Corporation, a 100 year-old high tech electronics firm that began manufacturing presses. B.F. Goodrich, for example, was founded in 1870 as a manufacturer of fire hoses and conveyor belts for manufacturing. Today, they are an aerospace company. The Tandy Corporation, founded in 1898, was originally a maker of 
leather goods and is today a retailer of electronic products. Bally began making pinball machines and now is a large operator of gambling casinos and fitness centers.

Famously, IBM began as a maker of mechanical office equipment and today is primarily a service and consulting company.

\section{Strategic Capabilities As Quasi-Fungible}

The body of evidence, when taken in its entirety, suggests that managerial discretion can shape an organization's capabilities, but such discretion is by no means unlimited. Creating new capabilities is costly, time consuming, hard to fully predict and ultimately bounded. An organization like IBM may, over decades, evolve from a maker of mechanical office equipment to a computer company to an IT services and consulting company, but it is unlikely that IBM could have gone from being a computer company to an aerospace company or drug company overnight. Capability creation occupies a "middle zone" between the two extremes of, on the one hand, complete, unbounded fungibility (as seen through traditional economic theory lens) and, on the other hand, complete, history-determined inertia (as seen through a strong path-dependence lens). The fact that capabilities live in this "middle zone" is exactly what makes them strategic. If capabilities could be changed instantly and without cost, they could never confer an advantage. Rivals could quickly imitate advantageous capabilities, thus dissipating associated rents. On the other hand, if capabilities were a complete "straightjacket," then they would no longer be a strategic variable, and thus outside the realm of strategic analysis.

\section{Characterizing A Firm's Capability Strategy}

A capability-based perspective on strategy views competition as occurring at two levels. One is the visible level of product market competition. This level concerns familiar decisions like entry strategies, positioning and deterrence. This level is relatively "visible" because most strategic product market moves of firms are somewhat observable using public data sources (annual reports, press releases, market price data, etc.). It concerns such familiar strategy questions as "What kind of next generation aircraft should Boeing develop to gain an advantage over Airbus?"; "How should Apple position the Apple Watch relative to Samsung's watch-like device?"; "Should Honda enter the market for light private jets?"; and "What kind of alliances 
might Netflix form with internet service providers to gain an advantage over rivals in the video-ondemand market?" The other level of competition—much less visible to outsiders—concerns the competition to create operational, organizational, and technological capabilities. Here, we get into the "guts" of how organizations do things. This level of competition concerns such questions as: "How much should Apple invest in developing novel battery technologies?"; "How heavily should BMW be investing in hydrogen fuel cell technology (vs. alternatives)?"; "How much should Boeing be investing in 3D manufacturing processes?" and "Should Amazon be investing heavily in the software required to make drone delivery safe and reliable?" These capabilities result from a host of activities such as formal R\&D programs, experimentation, autonomous learning, training, human resource initiatives, process re-engineering improvement, and the like. Scholars and practitioners have historically viewed these kinds of "engineering" and "operating" decisions as outside the realm of strategy. A capabilities-based view of strategy says that if these decisions change the terms of competitive advantage, they are, in fact, quite central to strategy.

A capabilities-based theory of strategy should link product level competition and capability-level competition. It should help us understand how the dynamics of product market competition may influence the capability strategies pursued by different rivals, and conversely, it should help us understand how rivals' "bets" on different capability strategies could influence product market competition. Normatively, it should help managers identify which types of capability improvement trajectories are likely to provide an advantage.

\section{The Strategic Choice Set}

Strategy is always and everywhere about irreversible choices and trade-offs. ${ }^{6}$ Choice is the focal point of strategic analysis. A robust strategy theory must be clear about the set of choices that fall under its analytical umbrella. Porter's competitive forces framework (1980), for instance, was quite clear that a firm's strategy consisted of choices about which markets to enter and whether to position as a "low cost" or "differentiated" player in those markets. Game theoretic

\footnotetext{
${ }^{6}$ See for instance Ghemawat (1991) and Porter (1991)
} 
models of strategy have been equally crisp in spelling out specific strategy choices faces by firms (e.g. to add capacity ahead of competitors or to wait). Resource-based theories focus on choices about market entry and positioning.

What is the firm's strategic choice from a capabilities perspective? Dierickx and Cool (1989) provide early insight into this question: "[A] key dimension of strategy formulation may be identified as the task of making appropriate choices about strategic expenditures (advertising spending, R\&D outlays, etc.) with a view to accumulating resources and skills (brand loyalty, technological expertise, etc.). Teece and Pisano (1994) similarly offered that a firm's strategic problem was to choose among alternative investment paths for building capabilities that would underlie competitive advantage. However, since that time there has been relatively little progress in characterizing the specific capability investment choices faced by firms. As noted earlier, the vast chunk of work on dynamic capabilities has not focused on choices, but rather on adaptability. This has impeded progress on a strategic theory of capabilities.

At any point in time, a firm possesses a repertoire of capabilities that span a continuum from general-purpose (e.g. mechanical engineering, organic chemistry, assembly manufacturing, quality improvement, financial management, etc.) to highly application-specific (compact car design, immunotherapeutic cancer drug discovery, semiconductor manufacturing, etc.). The firm's capability strategy problem involves choices about investments that either deepen their existing capabilities or broaden their repertoire to include new sets of capabilities.

\section{General Purpose Know-How vs. Application-Specific Know-How}

Following Winter's (2003) definition, a capability is a collection of organizational routines that enable a firm to perform some set of tasks on a repeatable or consistent basis. The span of tasks that can be performed depends on the nature of the underlying knowledge. At one extreme, we can think of "general-purpose know-how" which can be deployed in a relatively broad range of uses. For instance, auto companies deploy a lot of mechanical engineering know-how in the 
design and manufacture of vehicles, but mechanical engineering is by no means unique to carsit is used in the design of motorcycles, airplanes, medical devices, toys, furniture, and consumer electronics to name just a few. But it takes more than raw mechanical engineering know-how to design a competitive car. Car design also requires the application of idiosyncratic knowledge specific to vehicles (and unique to a company's rendition of a specific vehicle). This type of knowledge is referred to as application-specific knowledge. ${ }^{7}$ For instance, designing a car chassis requires solving a host of specific engineering problems associated with the unique requirements and uses of a car (e.g. the chassis is stressed at different points depending on the weight of the vehicle, the conditions of the road, the speed of the vehicle, the RPM of the engine, whether the vehicle is turning, breaking, or accelerating, etc.). And knowledge about how to design a chassis for a BMW 3-series is not exactly the same as what is required to design a chassis for a full-sized Ford pick-up truck. That same knowledge about chassis design for a car, however, does not necessarily transfer to the design of a motorcycle (where a key challenge involves figuring out the weight distribution to ensure stability of 2-wheeled vehicle).

Application-specificity is a matter of degree, not kind. For instance, designing cars and airplanes share more in common than designing cars and discovering cancer drugs. But designing a car has unique aspects relative to designing airplanes. And within the broad realm of cars, there are significant differences in skill sets required. Designing a $\$ 15,000 \mathrm{Kia}$ Soul is a fundamentally different engineering task than designing a $\$ 300,000$ Ferrari F12Berlinetta (which might have more in common with designing a small airplane). Application-specificity comes down to the degree to which knowledge is transferable across tasks or contexts (e.g. product categories, market segments, operating constraints, and geography). Differences in tasks and context may be quite subtle. For instance, Walmart knows how to effectively operate large, low cost supermarkets throughout the US—but that same capability does not seem to have transferred well to many markets outside the US (e.g. Germany). While the differences between general purpose and application-specific knowledge are a matter of degree, I will talk about them

\footnotetext{
${ }^{7}$ For earlier discussions of application specific know-how, see Winter (1987) and Breschi and Malerba (1997)
} 
as discrete choices for convenience.

At first glance, it might seem that firms would only ever want to invest in highly application-specific capabilities. After all, the literature on capabilities has long argued that only idiosyncratic capabilities can underlie a competitive advantage. But this thinking ignores the fact that general-purpose capabilities provide a necessary foundation for application-specific capabilities. Consider the use of genomics to identify promising drugs to treat cancer. Advantage comes from unique capabilities to apply genomics (along with other bodies of scientific knowledge) to identify cancer drugs. But, this also requires mastering quite a bit of knowledge about genomics, which is potentially applicable in to a broad range of therapeutic areas, as well as for developing products in agriculture, specialty chemicals, and energy. While it may not be sufficient for advantage, general-purpose know-how is necessary.

General-purpose know-how is also strategically important because it shapes a firm's future potential market entry options. Investments in a given body of general-purpose know-how delineate a set of options for future investments in application-specific know-how. For instance, a drug company's investments in genomics (general purpose) create a set of future options for application-specific investments in a variety of therapeutic areas (cancer, diabetes, etc.). Google's general-purpose know-how in computer science and information technology has created options for it to make application-specific investments in driverless vehicles. Because general-purpose know-how is (by definition) more transferable across contexts and markets, it provides the firm future strategic growth options. Investments in highly application-specific knowhow also involve a trade-off. They may deepen the firm's advantage in a specific market, but because of their inherent non-transferability, they may also constrain the firm's future market entry strategies. Choices about capabilities-which existing ones to deepen and which new ones to attempt to create-have consequence for market entry strategies.

Deepening vs. Broadening 
As discussed earlier, capability formation results from various kinds of activities, including formal R\&D projects, technology adoption, investments in physical and human capital, experimentation, business process redesign, and autonomous learning by doing. For convenience, I will refer to these types of capability creating activities as "investments". Investments can be aimed at deepening the firm's existing capabilities or at broadening the firm's repertoire into capabilities. Both general-purpose and application specific know-how can be subjected to deepening or broadening investments. Figure 1 below illustrates the choice space for capability enhancing investments, along with some illustrative examples.

Figure 1: Mapping Capability Strategy Choices

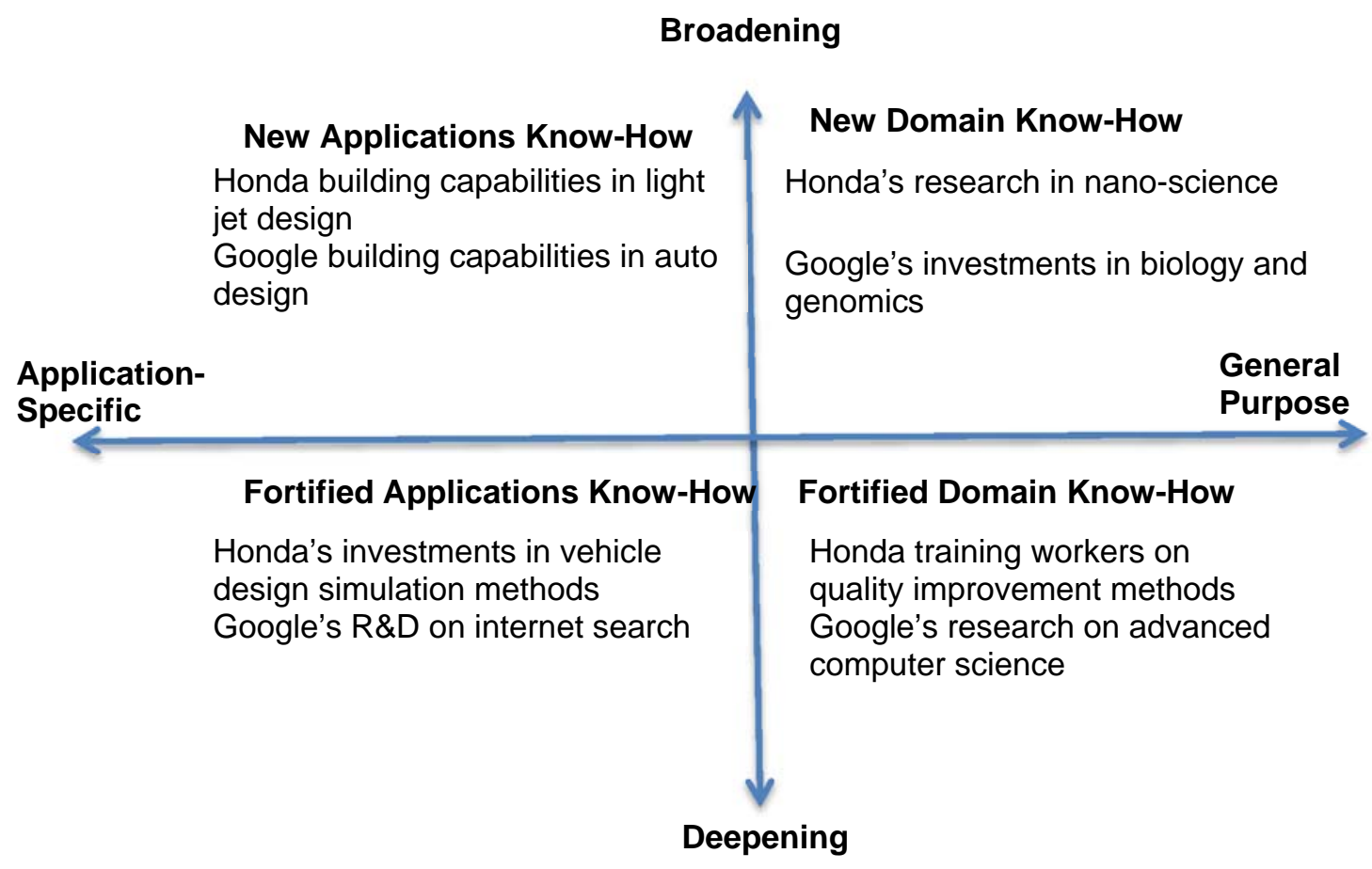

At any point in time, companies may make multiple types of capability enhancing investments (as 
the examples above were also designed to illustrate). It should also be clear that certain strategies might require investments in specific combinations of new capabilities. For instance, as Google pursues a strategy to enter markets like vehicles and health care, it must both broaden its general-purpose know-how (e.g. hardware and mechanical design for cars, medical science for health care) as well as its application-specific know-how (e.g. vehicle design, diagnosis of mental health problems, etc.). A firm's allocation of investments across different types of capabilities defines its capability strategy.

\section{Connecting a Firm's Capability Strategy to Product Market Competition}

In practice, different firms likely pursue very different capability strategies. Some may focus heavily on deepening application-specific know-how, while others may be putting more resources into broadening both general purpose and applications know-how. As is the case for all strategy decisions, there is no "one best way", but a series of trade-offs that need to be evaluated against competitive conditions. As mentioned earlier, a robust capability-based theory of strategy should connect firms' capability investment choices with product market competition.

To simplify matters, let's consider three fairly broad contexts: 1) Stable Competition whereby a firm competes against existing incumbent rivals in an existing market (e.g. Apple vs. Samsung in mobile computing devices; Ford vs. GM in automobiles; Airbus vs. Boeing in large aircraft. 2) Schumpeterian Entry whereby an incumbent firm faces the threat (or reality) of entry from new rivals armed with new capabilities (incumbent automobile companies vs. Tesla in automobiles; watch companies vs. Apple in wearable computing devices, newspapers vs. Google in advertising). 3) Penrosian Dynamics whereby an existing firms seeks to enter a new market that requires the creation of at least some new capabilities (Amazon's entry in Web Services; Netflix's entry into entertainment content creation, Virgin Group's entry into businesses as diverse as airlines, trains, mobile telephony, radio, broad band internet, fitness, health care, insurance, 
banking, space travel, etc.). I choose these three competitive circumstances strictly for illustrative purposes rather than to argue that they constitute the entire universe of competitive situations. They do not. They are different enough from one another, however, to begin to see how competitive context may be expected to influence capability strategies.

\section{Stable Competition}

It is popular today to talk about how competition has become highly turbulent and subject to sweeping forces of "disruption" and "hyper-competition." In reality, many industries are characterized by relatively stable competition between a reasonably limited set of long-standing rivals who compete against one another in well-defined product market spaces. These would include such stable oligopolies as the airframe industry, the jet engine industry, the auto industry (until very recently), microprocessors, banking, insurance, food processing, agriculture, petroleum, tires and chemicals. Stable product market structures, however, do not necessarily imply static capability strategies. Contrary to the view often expressed in the dynamic capabilities literature (starting with Teece, Pisano, and Shuen 1997), the creation of new capabilities is not limited strictly to "highly dynamic" product markets. Beneath the seemingly placid surface of product market competition, firms may be investing heavily in the creation of new technological, operational or distributional capabilities in order to gain advantage. Capability creation and renewal is just as important in stable competitive contexts as they are in more turbulent ones.

Consider the auto industry. In many ways, it is the perfect picture of a (mature) stable competitive context. The top ten producers account for $81 \%$ of global sales; and, among the top ten, eight have very long histories in the business (VW, Toyota, GM, Renault-Nissan, Ford, Honda, Peugot, Fiat-Chrysler). The top three players (VW, Toyota, and GM) account for over a third of the global market. Market shares certainly evolve over time, but changes of greater than $1 \%$ in a year are the exception, not the norm.

Yet, the auto industry is far from static in terms of capability creation. Auto companies 
are among the largest R\&D spenders in the world. In 2014, Volkswagen invested \$13.5 billion in $R \& D$, more than any other company in the world (for comparison, that is about $65 \%$ more than Google spent). Six automobile companies (VW, Toyota, GM, Ford, Daimler, and Honda) rank among the top 20 R\&D spenders worldwide in 2014. Auto companies have competed intensely to create new technological and manufacturing capabilities (Fujimoto 1999). The time it takes to develop a vehicle has been cut in half over the past two decades by creating new organizational capabilities (via changes in development process, project team structures, etc.) and new technological capabilities (e.g. computer aided design and virtual prototyping via computer simulation). Manufacturing capabilities as well have been transformed by changes in organization (e.g. work force management, supplier management) and technology (e.g. automation). While many of these capabilities are not the kind of "disruptive" innovations that garner a lot of attention, they none-the-less shape competitive outcomes in the industry (Fujimoto 1999). GM and Toyota are similar companies. They are among the largest in the industry; both have long histories; both offer comparably broad product lines and sell in essentially the same global markets. Their product market strategies are similar. Yet, they have experienced very different competitive fortunes. This can largely be explained by differences in product development capabilities that influence development lead times, engineering productivity, design quality (Clark and Fujimoto 1990, Fujimoto 1999), and manufacturing capabilities that shape product costs and quality (Womack et al. 1990).

The microprocessor business is a similar case where intense capability competition occurs amidst a relatively stable product market. The microprocessor market has been about as stable an oligopoly (near monopoly) as there is. Intel has maintained a near iron grip on the market for more than three decades, with market share ranging between approximately $80 \%$ and 98.5\% (the rest being captured largely by AMD). Innovation has been very rapid, yet largely evolutionary (extensions of the Intel X86 architecture). Yet, from a capability creation point of view, this is a highly dynamic industry. Intel is the world's third largest spender on R\&D (\$10.6 billion in 2014) and one of the world's largest investors in new plant and capital equipment (\$11 
billion in 2014). It has incessantly pushed the leading edge of both microprocessor design and semiconductor manufacturing processes to create ever more powerful and functional devices (the most recent example of which is a three dimensional chip fabrication technique known as FinFET). Certainly, Intel's dominance is due to a variety of strategic actions (Pisano 2001, Yoffie and Sind 2005), but it would be hard to dismiss the fact that Intel has done a far better job than AMD in creating the design and manufacturing capabilities that matter most in the microprocessor market.

The auto and microprocessor cases are great reminders that capability creation and renewal matter even in markets not undergoing competitive upheaval. No, these are not "radical" or "disruptive" innovation contexts where core product concepts are fundamentally changing (although as discussed later, the auto context may be on the verge of changing). Much of the innovation in automobiles and in microprocessors has been routine. It builds upon and extends existing product and process concepts. Because of its focus on "adaptability," the current dynamic capabilities literature would dismiss these contexts as uninteresting (in fact, it is likely that firms like Intel or Toyota would not even qualify as having the illusive "dynamic capabilities" because they have yet to prove they can adapt to radical change). But routine innovation does not mean the underlying capabilities for product development and manufacturing (or other parts of the business) are static. They are not. Capabilities are created and renewed even where product market competition is relatively stable.

One common characteristic of stable product markets is that competition tends to center around a few long-standing attributes (in microprocessors, the name of the game is processing speed; in aircraft, competition revolves around "costs per seat mile"). As a result, capability creation tends to occur along fairly well-defined trajectories that drive those key competitive attributes (Dosi 1982). In microprocessors, for instance, processing speed is driven largely by density and greater density depends on ever-smaller line widths. Advantage stems from understanding how customers' needs for specific products are evolving and the potential 
technical solutions that may fill the gap between expected and actual product performance. This requires deep and nuanced understanding of the specific product technologies, the specific market and the target customer segments and how customers use the product. I would conjecture that deepening application-specific know-how would be the predominant capability strategy in stable product market contexts.

One defining characteristic of stable product markets is that, in the absence of some shock (which we discuss in the section below on Schumpeterian dynamics), market leaders tend to remain leaders (and laggards stay laggards, see e.g. Gort 1963, Porter and Caves 1978, Chandler 1990, Sutton 2007). We also have some scattered evidence of capability persistence from a few industry case studies (e.g. Chandler 1990; for semiconductors, see Dosi 1985 and Malera 1986; for automobiles see Womack et al. 1990 and Fujimoto 1999). While much more empirical research is required to establish the link between market leadership and capability leadership in stable markets, let us assume for now the stylized fact of persistent capability leaders. Persistent capability leadership is a puzzle. Why do laggards have a hard time "catching up"? Capability competition focused on application-specific know-how provides a possible explanation. In general, application-specific know-how builds cumulatively, involves learning-bydoing, revolves around tacit knowledge, and is difficult to imitate (Winter 1987, Breschi and Malerba 1997). Together, these characteristics go a long way toward explaining a persistence of capability leadership. An interesting topic for future research is whether capability strategies focused on application-specific knowledge are the cause or the result of a stable competitive context.

\section{Schumpeterian Entry}

Stable industries discussed above are not inherently stable forever. Technological and business model innovation (often from new entrants) can create potentially destabilizing changes in competitive positions. The why established firms fail literature goes back to Schumpeter, of course, but saw a resurgence in the 1980s and 1990s with a number of seminal contributions 
elaborating on the underlying causes of Schumpeterian creative destruction (e.g. Tushman and Anderson 1985, Henderson and Clark 1990, Suarez and Utterback 1995, Christensen 1997). Unlike the case for stable competition above, Schumpeterian competition has drawn a number of in-depth industry case studies that explore the rich details by which specific technologies have evolved, and the challenges of specific organizations in responding (in addition to the seminal pieces cited above, see also Klepper 1997; Tripsas and Gavetti 2000; King and Tucci 2002; Bresnahan, Greenstein, and Henderson 2011; and O'Reilly and Tushman 2008).

The consensus from the literature is that, as predicted by Schumpeter, dramatic changes in either the technological or market environment put incumbents at high risk of failure (but as pointed out by O'Reilly and Tushman (2008), failure is not a foregone conclusion and some firms seem to have the capacity to adapt—what they call a dynamic capability). The more controversial question is why? Different literatures have posited different underlying causal mechanisms of failure.

The why successful firms fail literature raises, but does not fully answer, the question, how much do capabilities matter for firm survival in the face of Schumpeterian competition. Two theories-“disruptive innovation" (Christensen 1997) and "economies of scope" (Bresnahan et al. 2011) —imply that a firm's capabilities are relatively fungible, and that capability constraints play, at best, a second order role. That is, firms have the capacity to develop novel capabilities in response to Schumpeterian competitive threats but they fail to engage this capacity either because they are myopic (Christensen 1997) or because they are responding (rationally) to the real costs of redeploying common assets (Bresnahan et al. 2011). This stands in contrast to work on competence-destroying innovation (Tushman and Anderson 1985, Henderson and Clark 1990, Leonard-Barton 1992) that paints a far more constrained view of the ability of firms' to create the needed new capabilities to fend off entrants.

The distinction between general-purpose knowledge and application-specific knowledge 
may help provide some predictable hypotheses to resolve this question. Typical Schumpeterian shocks involve new entrants armed with some novel general-purpose capability pitted against incumbents armed with deep application specific know-how. Consider the increasingly less hypothetical situation of Google entering the car industry (either directly or via alliance) with some type of autonomous vehicle. Google would be a classic Schumpeterian entrant in that its generalpurpose capabilities in information technology, data science, digital design, and communications have not been historically part of the repertoire of automobile companies. Automobile companies know a lot about developing and manufacturing cars (application specific know-how) and have a number of fairly deep general-purpose capabilities in traditional "auto" fields (e.g. mechanical engineering, industrial design, high volume manufacturing, etc.). What they lack (to date) are the same general-purpose capabilities in information technology, data science, digital design and communications possessed by Google. Of course, what Google lacks (to date) are detailed capabilities in vehicle design and manufacturing accumulated by auto companies over decades, as well as some of the general purpose capabilities that underlie those (e.g. mechanical engineer, etc.). If you wanted to predict whether Google will "disrupt" the auto industry, you have to ask the question: will it be easier (faster) for Google to acquire the general purpose and applicationspecific capabilities in vehicles they lack or for automobile companies to acquire the general purpose capabilities in information technology they lack? Of course, major changes in underlying technology can also make obsolete some application-specific know-how that may have once been a barrier to entry (e.g. autonomous vehicles require a lot less attention to driver interface design and aesthetic aspects of "driveability" such as sporty handling). Schumpeterian entrants succeed when they are able to acquire the required application-specific know-how faster than incumbents can acquire the Schumpeterian entrants' novel general-purpose know-how (or when they can make that application-specific know-how obsolete).

Much of the research on Schumpeterian competition has focused on the challenges faced by incumbents in responding to new entrants. The framework above suggests that a key element of this challenge for incumbents concerns the development of new general-purpose 
know-how. And it raises a question for future research: are the organizational capabilities required for deepening application-specific know-how different from those required to broaden general purpose know-how? Again, consider the auto industry as an illustrative example. Even if incumbent auto companies recognize a potential threat from new entrants like Apple or Google, do they have the organizational capabilities to broaden their general purpose know-how (into say information technology and data science), after decades of focusing on deepening applicationspecific know-how (getting better at designing and manufacturing cars)? Current research has offered little empirical insight into these types of questions. While the literature focuses on the challenges of incumbents in Schumpeterian upheaval, this framework also sheds light on the potential challenges of new entrants. Specifically, it highlights the role of application-specific knowledge as a potential barrier to entry. More empirical work examining the challenges of broadening general-purpose knowledge (faced by incumbents) and broadening application specific knowledge (faced by new entrants) would provide a much better understanding of Schumpeterian dynamics.

\section{Penrosian Dynamics}

As Edith Penrose first pointed out in 1959, a common strategy for firm growth is to expand into new lines of business by utilizing common fixed resources. The Penrosian growth theory starts with the premise that firms make investments in a set of resources (like brand, distribution, technology, etc.) to serve their initial market. When these resources entail high fixed costs and cannot be fully utilized in the initial market, profitable opportunities exist for firms to use them in new markets. A number of scholars extended her core theories to develop robust explanations of the multi-product firm (Teece 1982) and to explain why diversification into "related" lines of business tended to be more profitable than "unrelated" diversification (Montgomery and Wernerfelt 1984, Teece et al. 1994). The core theoretical elements of Penrosian growth process are economies of scale (which lead to assets being under-utilized in "core" markets), economies of scope (which enable assets to be deployed into new markets with low marginal cost) and transaction cost economics (which make it more profitable for a firm to 
capture rents on these assets via internal diversification than through licensing). Overall, a resource-based perspective provides a relatively coherent picture of growth through diversification.

There is a puzzle, however, that cannot be explained by a pure resource-based perspective. Diversification is almost never purely a process of exploiting existing assets; it usually requires the creation of some combination of new general-purpose know-how and new application-specific know-how. Consider the example of Virgin Group (for details, see Pisano and Corsi 2012), which diversified into a broad range of businesses, including music, airlines, trains, radio, broadband communication, fitness centers, insurance and banking, gaming and, most recently, primary care physician practices. From a resource-based perspective, this is a simple story of Virgin leveraging its powerful brand that has come to stand for excellent (and entertaining) customer service. ${ }^{8}$ But, operationally, these businesses are very different. The capabilities to run an airline are completely different than those required to operate a bank or a fitness center. While Virgin outsources a lot of "back-end" operations and infrastructure to third parties, its operating companies still need to create capabilities that do not appear to be part of the existing Virgin repertoire. Or consider the recent entry of Honda into the light private market. Broadly speaking, jets and cars (and motorcycles and lawn and garden equipment) both utilize similar general-purpose capabilities in mechanical engineering and (increasingly) electronic engineering. However, to describe Honda's diversification strategy as leveraging "core competences" in mechanical engineering would be to completely ignore the high degree of specialized design capability required in each of these segments. An airplane is not a car with wings. The move into light jets almost certainly required Honda to invest in and learn new application-specific capabilities idiosyncratic to aircraft.

Teece et al. (1994) attempt to explain the patterns of diversification of firms within a

\footnotetext{
${ }^{8}$ With the exception of primary practices in the UK, Virgin always uses the Virgin brand in its new businesses (Virgin Atlantic, Virgin Active, Virgin Casino, Virgin Mobile, Virgin Money, etc.).
} 
Penrosian framework. Empirically, they found patterns in firms' diversification moves that suggested a degree of "coherence"; theoretically, they argue that these patterns can be explained by such factors as technological opportunity, learning, path-dependence, and selection. While they propose that coherence results from the incremental, cumulative (path dependent) nature of firm learning, they do not elaborate on what drives the range options. For instance, they hypothesize (page 17), "If firms attempt to enter new markets with new technologies, failure is likely to be the norm because the effort is likely to be outside the firm's learning range (italics added)." What the learning range is for any given firm, however, is not specified. How broad or narrow is this "learning range"? Is the learning range more constrained by general-purpose knowhow (say learning medical science if your expertise is in computer science) or application-specific know-how (learning how to design jets if your expertise is in cars). Is the "learning range" a function of the firm's experience with past capability broadening moves?

Predicting the success of these capability-broadening strategies is challenging. The problem is that we lack good theories to help managers predict how far they can broaden the application-specific and general-purpose capabilities of the firm in order to serve new product or geographic markets. Outside the extremes of either trivial leveraging (Honda developing a next generation car) or heroic leaps (Honda developing a cancer drug), we have no real basis to distinguish the vast intermediate space (Honda developing a lightweight jet). Yet it is exactly in this middle ground where companies' most important strategic capability decisions must be made. Finding insights into the true limits of firms' capability broadening moves should be a focal point for future research.

\section{CONCLUSION}

Everyday, in enterprises throughout the world, managers make decisions about investments and other interventions that influence their firm's capabilities. These decisions, in turn, have consequences for competitive advantage. As such, they are central to the study and practice of competitive strategy. This was a central tenet of the "dynamic capabilities" framework 
when first proposed two decades ago. Strategy is a normative field, and thus strategy theories must ultimately be judged by how well they inform practice. From this perspective, the dynamic capabilities research program to date has not delivered despite intensive effort by many talented scholars. The dynamic capabilities literature has become mired in endless debates about definitions (which has lead to introduction of even more terminology). At the same time, it has failed to address the most important questions of practice a theory of strategy must ask. The existing dynamic capabilities literature, by focusing heavily on firms' generalized capacity for adaptation to change, does not provide much insight about strategic choices. Certainly, a firm with a greater capacity for change will have more strategic options than one that is more inert. Such flexibility is no doubt a good thing for an organization. Research that helps us understand organizational flexibility is certainly worthwhile. However, understanding what makes an organization flexible is different from understanding what makes it competitive. The latter is the strategic problem faced by practitioners. The gap been the problems of management practice and the focal problems of the dynamic capabilities literature is striking.

In this essay, I have tried to sketch the outlines of a possible path forward to address this gap. I started with the premise that firms compete at two levels: they compete in product markets and they compete in the creation of capabilities that provide them advantage in those markets. These two levels are linked. Competitive conditions impact capability choices and capability choice shape competitive conditions. While we know quite a bit about competition in product markets (thanks to decades of research in industrial organization and strategic management), we still know relatively little about how firms should think of competing in the creation of capabilities. This paper has argued that a firm's capability strategy can be defined as its pattern of investment in different types of capabilities. The paper offered a simple typology of capabilities based on two dimensions. One dimension is the degree to which investments are made in general-purpose versus application-specific know-how. The second dimensions concerns whether the investment is focused on deepening the firm's existing capabilities or on broadening its repertoire to encompass new capabilities. 
Strategic choices, by definition, involve trade-offs. By focusing on the distinction between general-purpose and application-specific investments, the framework here brings trade-offs to the issue of capability selection. There is no type of capability that is inherent superior to another. Each choice along the spectrum of general purpose to application specific brings a different set of trade-offs. Investments in general purpose know-how creates future investment options in application-specific know-how. These, in turn, provide the firm future growth options (via Penrosian diversification strategy) or provide the firm the potential to respond to Schumpeterian entry threats. But there is a cost: general purpose-know by itself does not convey strategic advantage in product markets. Application-specific know-how is required. In contrast, deepening application-specific know-how can bolster competitive position in an existing market, but at the cost of restricting future growth options.

One conjecture arising from this framework is that the value of different kinds of capabilities (and thus different kinds of capability strategies) is contingent on the nature of competition faced by the firm. Contrary to the existing literature, I have argued that even in markets characterized by relatively stable competition, capability competition can be intense. But my conjecture was that in this type of competitive situation, capability competition revolves around deepening application-specific know-how. Where application-specific know-how is highly cumulative and highly appropriable, we would expect the persistence of capability leadership. In markets undergoing some type of Schumpeterian "shock", the nature of capability competition shifts toward broadening of both general purpose and application-specific know-how. The framework presented here gives us a way to think about the potential outcome of a Schumpeterian shock (not all of them lead to the downfall of incumbents). The outcome of a Schumpeterian shock may depend on the extent to which incumbents' existing applicationspecific know-how advantage over new entrants is preserved or made obsolete by changes in general-purpose knowledge. Where application-specific know-how is preserved, incumbents likely have higher chances of survival. The framework also gives us a way to think about the likely success of Penrosian diversifications strategies. The typical Penrosian growth story is one of leveraging capabilities and resources across "related" markets. However, entry into any new 
market (even the most "related") requires a firm to develop new application-specific know-how. The success of a Penrosian diversification strategy depends on the firm's ability to broaden its application-specific know-how and on the inherent difficulty of acquiring or emulating such knowhow. Where learning application-specific know-how is difficult (say because it is highly tacit or highly proprietary), Penrosian growth strategies are likely to fail.

The framework developed in this paper is a complement to, rather than a substitute for, other research on dynamic capabilities. It recognizes that firm's choices are partially constrained by past decisions (but, to emphasize, firms are not complete prisoners of their past choices either-they have discretion). It is also not inconsistent with the possibility that some firms may have greater ability to expand and reconfigure their capabilities. That is, some firms may be more adaptable (or have greater "dynamic capability" to use the language of the extant literature). The differences are ones of focus. The framework developed in this paper emphasizes choices of capability investments, rather than adaptability, and tries to provide some helpful way to think about the consequences of those choices.

My major goal in this essay has been to identify important gaps in our theoretical and empirical knowledge as a means to focus future research in productive directions. Let me close by highlighting a few of these. First, a major empirical gap concerns the typical patterns of investments by firms in different capability enhancing efforts. We simply do not know, for instance, how much firms in different industries tend to devote to deepening or broadening their general-purpose and application-specific know-how, and how successful these investments tend to be. This would be a good starting point to assess whether certain kinds of capability strategies are associated with different kinds of product market strategies and competitive situations. Similarly, we have little insight about the challenges firms face in developing new applicationspecific know-how Is it easier in some contexts that others? When is such application-specific know-how relatively easy to imitate or acquire? In contrast, when is it a potent barrier to entry? I offered some conjectures in this paper as a way to motivate discussion, but empirical work on the topic is sorely needed. 
A second big gap in theoretical and empirical knowledge concerns judgments about the range of capabilities any given firm can pursue over some specific time period. For both Schumpeterian entry and Penrosian dynamic contexts, competition involves races to create new application-specific and new general-purpose know-how. As of now, we have no real way to predict theoretically how such competitions will pan out. We do not know which broadening moves are likely to succeed and which ones will fail (beyond the obvious extremes). I have argued that a strategic theory of capabilities needs to focus on the "middle ground" of capabilities that are neither trivial for the firm to create in the short-term nor impossible to create over the long-term. But this "middle ground" is broad, and much more empirical research needs to be done to help identify systematic factors that shape which capability expansions are economically feasible and which ones are not. Without such insight, we do not have the basis for a normative theory that can guide practice.

A third gap ripe for research concerns what is required for a firm to alter its capability strategy. For instance, if a firm has focused for the past several decades on applicationdeepening investments, how difficult is it to shift course to a strategy focused more on broadening application-specific know-how or general-purpose know-how? Are there high-level organizational routines (like governance structures, resource allocation processes, etc.) that influence which capability strategies are open to the firm at any given time? We simply have no data on this subject to even speculate.

Addressing the above gaps will require in-depth longitudinal investigations of the evolution of specific technological and operating processes within firms and industries. We will need to examine the allocation of investment resources across different kinds of capabilities and the consequences of those decisions for operating performance. We will need to understand a lot more about the details of capability creating projects, and why some work and some fail. These kinds of data are typically not found in public sources, but require researchers to go into the field and inside organizations to capture primary quantitative and qualitative data. While such studies 
have fallen out of favor in academia in the recent past, they will be absolutely essential if we are to make significant progress on a topic of enormous importance to the practice of management. 


\section{References}

Abernathy, William J. and Kim B. Clark. "Innovation: Mapping the Winds of Creative Destruction." Research policy 14.1 (1985): 3-22.

Abernathy, William J., Kim B. Clark, and Alan M. Kantrow. Industrial Renaissance: Producing a Competitive Future in America. New York: Basic Books, 1983.

Adler, Paul S., and Kim B. Clark. "Behind the Learning Curve: A Sketch of the Learning Process." Management Science 37.3 (1991): 267-281.

Amit, R, and P. Schoemaker. "Strategic Assets and Organizational Rent." Strategic Management Journal 141 (1993): 33-46.

Andrews, Kenneth. The Concept of Corporate Strategy. Irwin: Homewood, 1971.

Argote, Linda and Dennis Epple. "Learning Curves in Manufacturing." Science 247.4945 (1990): 920-924.

Barney, Jay. "Strategic Factor Markets: Expectations, Luck, and Business Strategy." Management Science 32.10 (1986): 1231-1241.

Barney, Jay. "Firm Resources and Sustained Competitive Advantage." Journal of Management 17 (1991): 99-120.

Bloom, Nicholas and John van Reenen. "Measuring and Explaining Management Practices Across Firms and Countries." The Quarterly Journal of Economics 122.4 (2007):1351-1408.

Bloom, Nicholas and John Van Reenen. "Why Do Management Practices Differ Across Firms and Countries?" Journal of Economic Perspectives 24.1 (2010): 203-24.

Breschi, Stefano and Franco Malerba. "Sectoral Innovation Systems: Technological Regimes, Schumpeterian Dynamics, and Spatial Boundaries." in Charles Edquist (ed.), Systems of Innovation: Technology, Institutions, and Organization. Oxon, UK: Pinter (1997): 130-152.

Bresnahan, Timothy F., Shane Greenstein, and Rebecca M. Henderson. "Schumpeterian Competition and Diseconomies of Scope: Illustrations From the Histories of Microsoft and IBM." in J. Lerner and S. Stern (eds.) The Rate and Direction of Inventive Activity Revisited. University of Chicago Press (2011): 203-271.

Caves, Richard and Michael Porter. "Market Structure, Oligopoly, and Stability of Market Shares." The Journal of Industrial Economics 26.4 (1978): 289-313.

Chandler, Alfred. Scale and Scope: The Dynamics of Industrial Capitalism. Cambridge, MA: Harvard University Press, 1990.

Christensen, Clayton. The Innovator's Dilemma: When New Technologies Cause Great Firms to Fail. Boston: Harvard Business Review Press, 1997.

Clark, Kim and Takahiro Fujimoto. Product Development Performance: Strategy, Organization, and Management in the World Auto Industry. Boston: Harvard Business School Press, 1990.

Dierickx, Ingemar and Karel Cool. "Asset Stock Accumulation and Sustainability of Competitive Advantage." Management Science: vol 35, no 12 (1989): 1504-1511.

Dosi, Giovanni. "Technological Paradigms and Technological Trajectories: A Suggested Interpretation of the Determinants of the Direction of Technical Change. Research Policy, 11 (1982): 147-162. 
Dosi, Giovanni. Technical Change and Industrial Transformation. New York: St. Martin's Press, 1984.

Dosi, Giovanni, Marco Faillo, and Luigi Marengo. "Organizational Capabilities, Patterns of Knowledge Accumulation and Governance Structures in Business Firms: an

Introduction." Organization Studies 29.8-9 (2008): 1165-1185.

Dew, Nick, Brent Goldfarb, and Saras Sarasvathy. "Optimal Inertia: When Organizations Should Fail." Advances in Strategic Management 23 (2006): 73-99.

Edmondson, Amy C., Richard M. Bohmer, and Gary P. Pisano. "Disrupted Routines: Team Learning and New Technology Implementation in Hospitals." Administrative Science Quarterly 46.4 (2001): 685-716.

Fujimoto, Takahiro. Evolution of a Manufacturing System at Toyota. Oxford: Oxford University Press, 1999.

Garvin, David. Managing Quality. New York: Free Press, 1988.

Ghemawat, Pankaj. Commitment: The Dynamics of Strategy. New York: Free Press, 1991.

Gort, Michael . "Analysis of Stability and Change in Market Shares." The Journal of Political Economy (1963): 51-63.

Hannan, Michael T., and John Freeman. "The Population Ecology of Organizations." American Journal of Sociology (1977): 929-964.

Hayes, Robert H. "Strategic Planning-Forward in Reverse." Harvard Business Review 63.6 (1985).

Hayes, Robert and Kim Clark. "Why Some Factories Are More Productive Than Others." Harvard Business Review 64.5 (1986): 66-73.

Helfat, Constance and Margaret Peteraf . "Understanding Dynamic Capabilities: Progress Along a Developmental Path." Strategic organization 7.1(2009): 91.

Helfat, Constance and Margaret Peteraf. "Managerial Cognitive Capabilities and the Microfoundations of Dynamic Capabilities." Strategic Management Journal (2014).

Henderson, Rebecca and lan Cockburn. "Measuring Competence: Exploring Firm Effects in Pharmaceutical Research." Strategic Management Journal 15.S1(1994): 63-84.

Henderson, Rebecca and Kim Clark. "The Reconfiguration of Existing Product Technology and the Failure of Established Firms." Administrative Science Quarterly (1990): 9-30.

Iansiti, Marco.Technology Integration: Making Critical Choices in a Dynamic World. Boston, MA: Harvard Business School Press, 1998.

King, Andrew A., and Christopher L. Tucci. "Incumbent Entry Into New Market Niches: The Role of Experience and Managerial Choice in the Creation of Dynamic Capabilities." Management Science 48.2 (2002): 171-186.

Klepper, Steven. "Industry Life Cycles." Industrial and Corporate Change 6.1 (1997): 145-182.

Kuhn, Thomas. S. The Structure of Scientific Revolutions. Chicago: University of Chicago Press, 1962. 
Leonard Barton, Dorothy. "Core Capabilities and Core Rigidities: a Paradox in Managing New Product Development." Strategic Management Journal 13.S1 (1992): 111-125.

Lippman, Steven and Richard Rumelt. "Uncertain Imitability: An Analysis of Inter-Firm Differences in Efficiency Under Competition." Bell Journal of Economics 13 (1982): 413-438.

Malerba, Franco. The Semiconductor Business: The Economics of Rapid Growth and Decline. University of Wisconsin Press, 1985.

Montgomery, Cynthia and Birger Wernerfelt. "Diversification,Rricardian Rents, and Tobin's Q." The RAND Journal of Economics 19.4 (1988): 623-632.

Nelson, Richard and Sidney Winter. An Evolutionary Theory of Economic Change. Cambridge: Harvard University Press, 1982.

O'Reilly, Charles A. and Michael L. Tushman. "Ambidexterity As a Dynamic Capability: Resolving the Innovator's Dilemma." Research in organizational behavior 28 (2008): 185-206.

Pisano, Gary. The Development Factory. Boston, MA: Harvard Business School Press, (1996).

Pisano, Gary. Science Business: The Promise, The Reality, and the Future of Biotech. Boston, MA: Harvard Business Review Press, 2006.

Pisano, Gary P., Richard M. Bohmer, and Amy C. Edmondson. "Organizational Differences in Rates of Learning: Evidence from the Adoption of Minimally Invasive Cardiac Surgery." Management Science 47.6 (2001): 752-768.

Pisano, Gary. "Teaching Note for 'Intel Corporation: 1968-1997” HBS case number 797137. Boston, MA: Harvard Business School Publishing, 2001.

Pisano, Gary and Elena Corsi “Virgin Group: Finding New Avenues for Growth." HBS Case Number 6122070. Boston, MA.: Harvard Business School Publishing, 2012.

Penrose, Edith. The Theory of the Growth of the Firm. Wiley: New York, 1959.

Peteraf, Margaret, Giada Di Stefano, and Gianmario Verona. "The Elephant in the Room of Dynamic Capabilities: Bringing Two Diverging Conversations Together." Strategic Management Journal 34.12 (2013): 1389-1410.

Porter, Michael. Competitive Strategy. New York: Free Press, 1980.

Porter, Michael. "Towards a Dynamic Theory of Strategy." Strategic Management Journal (1991): volume 12: 95-117.

Prahalad, C. K. and Gary Hamel. "The Core Competence of the Corporation." Harvard Business Review (1990): 235-256.

Rumelt, Richard. "Towards a Strategic Theory of the Firm," in Lamb, Robert B. (ed.) Competitive Strategic Management, Englewood Cliffs, NJ. Prentice Hall, 557-570, 1984.

Rumelt, Richard. "How Much Does Industry Matter? Strategic Management Journal 12.3 (1991): 167-185.

Sutton, John. "Market Share Dynamics and the 'Persistence of Leadership' Debate." American Economic Review 97.1(2007): 222-241.

Teece, David. "Toward an Economic Theory of the Multiproduct Firm." Journal of Economic Behavior and Organization 3.1 (1982): 39-63. 
Teece, David J., Giovanni Dosi, Richard Rumelt, and Sidney Winter. "Understanding Corporate Coherence: Theory and Evidence." Journal of Economic Behavior \& Organization 23.1(1994): 130.

Teece, David and Gary P. Pisano. "The Dynamic Capabilities of Firms: An Introduction." Industrial and Corporate Change 3.3 (1994): 537-556.

Teece, David J., Gary P. Pisano, and Amy Shuen. "Dynamic Capabilities and Strategic Management." Strategic Management Journal (1997): 509-33.

Tripsas, Mary. "Unraveling the Process of Creative Destruction: Complementary Assets and Incumbent Survival in the Typesetter Industry." Strategic Management Journal 18.1 (1997): 119142.

Tripsas, Mary, and Giovanni Gavetti. "Capabilities, Cognition, and Inertia: Evidence from Digital Imaging." Strategic Management Journal 21.10-11 (2000): 1147-1161. .

Tushman, Michael and Phillip Anderson. "Technological Discontinuities and Organizational Environments." Administrative Science Quarterly (1986): 439-456.

Upton, David. “What Really Makes Factories Flexible?" Harvard Business Review 73.4 (1995): 74-84.

Suarez, Fernando F. and James M. Utterback. "Dominant Designs and the Survival of Firms." Strategic Management Journal 16.6 (1995): 415-430.

Wernerfelt, Birger. "A Resource-Based View of the Firm." Strategic Management Journal 5.2 (1984): 171-180.

Winter, Sidney. "Knowledge and Competence as Strategic Assets." The Strategic Management of Intellectual Capital (1987): 165-187.

Winter, Sidney. "Understanding Dynamic Capabilities." Strategic Management Journal 24.10 (2003): 991-995. .

Womack, J., D. Jones, and D. Roos. The Machine That Changed the World. New York: Simon \& Shuster, 1991.

Yoffie, David and Michael Sind. "Intel Corporation: 1968-2003." HBS Case number 703427. Boston, MA.: Harvard Business School Publishing, 2005. 